\title{
Entrevista: Armando Malheiro da Silva
}

\author{
Moisés Rockembach \\ Doutor; Universidade Federal do Rio Grande do Sul, Porto Alegre, RS, Brasil; \\ moises.rockembach@gmail.com
}

O professor português Armando Manuel Barreiros Malheiro da Silva, LivreDocente da Universidade do Porto, Historiador, Filósofo, Arquivista e Bibliotecário, vem pesquisando sobre a Ciência da Informação e suas relações interdisciplinares há mais de 20 anos, em Portugal e em diversos países, com estreita relação com pesquisadores brasileiros. Esta entrevista foi concedida em 23 de junho de 2016, na cidade do Porto, Portugal, onde discorre mais especificamente sobre o modelo de avaliação do fluxo informacional. São abordadas questões como os paradigmas da informação, o conceito de informação e de dado, a avaliação arquivística e o Método Quadripolar.

\section{A ideia em fazer este diálogo seria no intuito de esclarecer e trazer essa teoria proposta pela Universidade do Porto, nomeadamente pelo professor Armando Malheiro e pela professora Fernanda Ribeiro, em relação à avaliação da informação, a avaliação do fluxo informacional e talvez poderíamos começar por esclarecer o próprio objeto que é tratado nesta avaliação.}

Prof. Dr. Armando Malheiro da Silva: Sim, acho que podemos e devemos começar por este ponto, porque eu considero que a confusão começa mesmo aí. Há inclusive quem o chame de modelo, há quem o chame de atividade profissional, quem considere a avaliação como atividade profissional por excelência do arquivista, aliás os arquivistas de uma forma corporativa tomam a si a avaliação como sendo a pérola, a sua jóia da coroa. E na verdade, como vamos ver, a teoria que está por trás dessa atividade é uma teoria datadíssima e que inclusive já está anacrônica, porque ela foi pensada nos anos 1950/1960 por 
Schellenberg, um norte-americano, que se preocupou efetivamente em estabelecer uma linha divisória para avaliar no sentido de permitir que se guardasse a documentação com "valor histórico" na impossibilidade de se guardar tudo. Partiu da constatação de que um fluxo documental ou, aquilo que os arquivistas gostaram durante muito tempo de chamar de "massas documentais acumuladas", tornou-se um pesadelo e ao tornar-se um pesadelo era preciso criar critério. E ele usou, inclusive, a palavra valor - valor primário, a documentação com valor primário; e o valor secundário ou histórico. $\mathrm{O}$ valor primário entende-se porque de algum modo tem um caráter muito concreto e é relativo à posse administrativa. Tem a ver com os produtores que usavam os seus próprios documentos como eles próprios queriam. Estamos a falar das massas documentais e administrativas para apreciar/determinar os prazos de documentação, não os arquivos pessoais, familiar ou de associações, mas de organismos do Estado, que é isso que preocupava e continua a preocupar quando se fala de avaliação. $\mathrm{O}$ valor secundário incluía aquela documentação que perde interesse de prova para o administrativo e este até já nem se importa de deitar fora ou de mandar para alguém - e o arquivista é visto um pouco como faxineiro, que vai lá tentar limpar o que já está a incomodar o administrativo e que poderá vir a ter interesse histórico. E o que é o interesse histórico? $\mathrm{Na}$ formulação de Schellenberg, que era também historiador, isso nunca ficou muito claro, porque havia aqui claramente uma incerteza e uma ambiguidade, uma subjetividade que persiste em todas as propostas de avaliação decalcadas nessa teoria, chamemos assim, de senso comum do Schellenberg. Por isso, a avaliação é uma atividade, um modelo, uma operação? Eis a questão... E foi por aqui, inclusive, que nós iniciamos nossa reflexão. E começamos a perceber que a avaliação que os arquivistas tanto prezam e que consideram efetivamente como sendo a sua pérola, a sua jóia da coroa, faz parte de algo mais vasto, que é a avaliação da informação e também da documentação, porque a informação quando se registra vira documentação. A avaliação dos documentos administrativos é que se chamou "a Avaliação do Fluxo Documental" e há outros tipos de avaliação: a avaliação dos termos e das linguagens documentárias e a avaliação do desempenho dos serviços. Encarada por esta 
perspectiva a avaliação já não é apenas uma atividade profissional, é algo mais, que convoca a necessidade de um enquadramento científico. E, portanto, se passamos de atividade para uma operação científica, saímos de uma prática, de um conjunto de procedimentos que um profissional tem por obrigação fazer, de uma forma estabelecida por portaria ou por uma tabela de temporalidade para uma operação metodológica e aí já não é preciso portarias nem tabelas de temporalidade, porque passamos para a discussão científica do método. E esta é que é a questão. A avaliação entra na categoria de método ou é uma atividade profissional baseada na criação e na publicação de tabelas de temporalidade? A pergunta exige uma resposta clara. E aqui começa a nossa resposta, dada no Porto. Trata-se de um trabalho que nós começamos a fazer desde o final da década de 90, começamos a tomar uma posição muito clara, começamos a encarar e a considerar - e a discussão tem que ser feita a partir daqui - a avaliação como uma operação científica.

\section{E sobre o método utilizado, qual é vossa proposta para se fazer a avaliação?}

Prof. Dr. Armando Malheiro da Silva: Pois, ora bem, como nós, entretanto, discutimos e a avaliação é um método, nós também viemos discutindo o método, como o sabes muito bem, e é, aliás, um paladino deste método, que o aprendeu aqui, quando esteve a fazer o seu doutorado e já o conheceu antes, quando fez a sua dissertação de mestrado. E sabes que nós fomos buscar uma proposta dos belgas, publicada pela Presses Universitaires de France (PUF) em $1974^{1}$, pensada para as Ciências Sociais, que se pode, de uma forma mais simplificada, chamar de Método Quadripolar. Alguns chamaram de investigação qualitativa, mas eu acho isso muito redutor. O Método Quadripolar é uma proposta metodológica para as Ciências Sociais e não é quantitativo ou qualitativo, é quantitativo-qualitativo, isto é, nas Ciências Sociais torna-se ridículo estar a discutir ou a separar o quantitativo do qualitativo, porque o quantitativo não tem que ser visto nas Ciências Sociais como uma exclusividade das Ciências Naturais, dos matemáticos, dos estatísticos. A Estatística também entra como abordagem técnico-metodológica nas Ciências Sociais. A qualidade 
tem, por seu turno, a ver com a interpretação, com a hermenêutica. Ora, o Método Quadripolar é pensado, sobretudo, para que o investigador use ferramentas, use técnicas que sejam mais adequadas à complexidade dos fenômenos que trabalha e os fenômenos que trabalha são fenômenos de natureza humana e social, que não são observáveis ou experimentáveis em laboratório, onde se pode pegar os ratinhos, metê-los lá e repetir a experiência "n" vezes. Quando lidamos com um fenômeno como a informação e a comunicação, que é algo que tem a ver com a natureza humana e social, temos pessoas. E como é que se trabalha com as pessoas? Através de inquérito de entrevista, inquérito de questionário, mas que podem ter respostas manipuladas, alteradas, que temos que fazer um tratamento estatístico muito cuidadoso e que, depois, também não podemos deixar de cruzar com outras ferramentas, como a observação participante, a entrevista para complementar o questionário e por aí adiante. Portanto, é fácil concluir que a avaliação cabe dentro do Método Quadripolar. Começamos a falar da avaliação pela área arquivística e eu tenho um primeiro artigo sobre avaliação em Arquivística, mas algum tempo depois, num processo evolutivo, eu e a Fernanda Ribeiro, publicamos um artigo mais completo, que é onde está a nossa proposta de critérios em que assenta esta operação e passamos a considerar a avaliação não uma atividade, mas uma operação metodológica e esta é a resposta para a questão com que iniciamos esta conversa. Portanto, para nós, a avaliação é uma operação metodológica que se encaixa dentro do Método Quadripolar e isso é colocado no artigo de 2004, e que o tens como referência certamente, que é o que saiu na revista Páginas $A \& B$, assinado por mim e pela professora Fernanda, e que tem o título de "A Avaliação de informação: uma operação metodológica” (RIBEIRO; SILVA, 2004). Já agora, uma informação interessante é que em 2014, esta mesma proposta foi inserida num livro da editora IGI Global (SILVA; RIBEIRO, 2014). Foi a tentativa que fizemos de passar para inglês uma proposta de operacionalização metodológica e que inclui, obviamente, a avaliação do fluxo, que é a que os arquivistas utilizam, junto com a avaliação do processo de indexação e a avaliação de desempenho. Portanto, nós colocamos a avaliação de documentos junto com outras formas de aplicar a avaliação dentro da área da Informação, naturalmente. 


\section{Gostaria de perguntar sobre os critérios estabelecidos nesta metodologia de avaliação: a pertinência, a densidade e a frequência. Como vocês chegaram a estes critérios e como eles se relacionam?}

Prof. Dr. Armando Malheiro da Silva: Esta pergunta é muito importante: entender tais critérios engloba perceber tudo o que eu disse até aqui sobre esta mudança de perspectiva. Estamos com uma operação metodológica e ela tem que ser rigorosa e, portanto, a preocupação, não se esconde, foi afastar da ambiguidade e da subjetividade, que bem intencionadamente Schellenberg fez, na época em que o propôs e da maneira como o podia fazer. Mas Schellenberg não pode continuar a ser evocado anacronicamente, porque está, obviamente, no seu tempo. Porém tem que ser visto já como desajustado da atualidade. Porque o tempo de Schellenberg já passou e a proposta serviu para aquele tempo. As fragilidades são evidentes e a principal fragilidade é que a proposta carece de rigor científico. Está eivada de senso-comum e é pouco científica. E para alterar esta falha original tínhamos que introduzir critérios de raiz científica. Isso altera tudo. Mas para criar esses critérios é preciso um foco preciso: qual é o objeto da avaliação? Ou seja, a avaliação é uma operação que incide sobre o quê? E aí entra a questão muito importante do fluxo. A informação produzida e posta a circular na tramitação natural subsequente pode ser avaliada, como podemos avaliar o processo de recuperação através de termos e de vocabulários controlados, que é uma das áreas core da Ciência da Informação na nossa perspectiva. Portanto, aí nós temos também a oportunidade de fazer a avaliação e já há textos e propostas clássicas de autores anglo-americanos sobre a avaliação na prática da indexação e nas linguagens documentais. Mas o que nos interessa fazer é a avaliação do fluxo, que é aquilo que de uma forma mais primitiva, mais anacrônica, se chamaria a avaliação das massas documentais acumuladas com que os arquivistas trabalham. E não mudamos apenas o nome, porque tem aqui uma inflexão importante: é fluxo documental, ou seja, é a informação que nasce na produção, segue os tais ciclos de vida e que tem que ser avaliada para ficar apenas aquela informação que tem a ver com a gênese, e 
aqui começa o ponto. Quais são os critérios? Qual é o foco? A informação é avaliada porque vai interessar à História? Ou a informação é e tem de ser avaliada porque tem a ver com o produtor? Este tópico é importantíssimo e eu não compreendo como os arquivistas lhe podem resistir até porque há na Arquivística uma tradição sólida, que vem dos autores holandeses do "Manual de Arranjo" de 1898, passa pela escola italiana e pelo inglês Jenkinson relativa à preponderância do contexto orgânico e organicidade ${ }^{2}$.

Os arquivistas sempre começaram a achar que isso era muito importante, mas não deixaram, ao mesmo tempo, de fazer cedências complicadas ao "princípio" temático-funcional em detrimento da organicidade. Agora o orgânico tem a ver com o contexto e, portanto, a informação é produzida num contexto e no contexto de produção não existem historiadores, existem administrativos, existem agentes, existem servidores públicos, existem funcionários que produzem documentos dentro de uma cadeia hierárquica e organizacional. Esses documentos são a tradução da ação dessa instituição e da respectiva organicidade. Portanto, nós temos que valorizar na avaliação o contexto e não o interesse que o historiador venha a manifestar. Nós colocamos o historiador não fora do jogo, mas obviamente num outro plano do jogo, ou seja, o historiador será um utilizador, entre outros, terá muita importância no plano do comportamento informacional, como usuário dessa informação, mas o foco aqui está em avaliar a informação dentro do contexto de produção. E, portanto, os critérios têm que ver com a memória efetivamente, mas não com a memória social que os antropólogos e os historiadores gostam de falar; aqui só interessa a memória organizacional ou institucional. A informação retida é uma informação necessária para a vida da instituição e nessa qualidade irá interessar, inevitavelmente, ao historiador. Ponto muito importante: ela não é guardada em função dos interesses do historiador, mas da instituição e do produtor, portanto, os critérios têm que ser internos e orgânicos. Por isso é que nós criamos o critério da pertinência, da densidade e da frequência. Em que o critério da pertinência, o primeiro e fundamental, quer dizer pertença e tem a ver com o fato da informação produzida pertencer a algo ou alguém. A missão da instituição, os objetivos principais e específicos da instituição, estão fixados nos 
estatutos, daí que a consulta destes seja inevitável e constante. E depois, toda a informação que estiver relacionada com a missão da instituição é uma informação que tem potencial para ser guardado na memória permanente. A conclusão final a tirar é: importa saber o que fica de permanente, o que fica de provisório ou de eliminável. Significa isto como exemplo: eu tenho uma escola, a escola tem uma missão, que é ensinar, não é pagar os salários para os professores, mas isso também não deixa de ter importância para a escola, pois sem professores não há ensino, pelo que a documentação relativa a essa missão ganha de imediato um grau de pertinência elevado. Em termos de pertinência, a despesa com os salários incluída nos processos dos professores não são de pertinência A, mas são de pertinência B. Pertinência A é o quê? Planos curriculares, os alunos, porque eu não ensino paredes, nem carteiras, eu ensino alunos. Claro que eu não vou dizer que os processos dos alunos não têm uma relação de pertença com a missão da Escola, daí serem de Pertinência B pelo seu cariz administrativo. Mas os planos curriculares, as disciplinas, os conteúdos, os exames dos alunos, as provas, tudo isso que tem a ver diretamente com a missão da instituição é pertença $\mathrm{A}$, portanto tem um potencial de guarda ou preservação elevadíssimo. O foco não é pensar no interesse do historiador, mas preservar na Escola a informação pertinente e, se é pertinente à Escola, terá valor de fonte para o historiador obviamente. Segundo a proposta de Schellenberg, o valor secundário é discutível e a forma encontrada de avaliá-lo pior ainda, no Brasil e em Portugal as comissões criadas para elaborarem as portarias de eliminação ou as tabelas de temporalidade em que participam atores/produtores e utilizadores finais para fixarem o que se guarda e o que se elimina distorcem por completo a natureza do processo valorativo. Na fase de avaliação científica, o arquivista não tem que discutir a conservação dos documentos com os historiadores; ele tem é que ter um conjunto de critérios que lhe permitam, sem ajuda dos historiadores, que são usuários e não produtores, avaliar com o máximo de rigor possível o fluxo informacional. $\mathrm{O}$ arquivista tem de estudar com o produtor se as séries documentais ou os documentos compostos e simples se encaixam ou não na Pertinência A e, seguidamente, consideram o critério da Densidade que tem a ver com aquilo que é uma informação mais acumulada ou parcial. De um lado, 
temos todos os documentos relativos a várias ações administrativas articuladas e, de outro, temos documentos simples correspondentes a cada uma dessas ações. A densidade dos processos é mais completa e rica do que a dos documentos simples, o que leva a eliminar estes e a conservar aqueles, porque a informação acumulada tem mais memória do que a parcial. Tão simples como isto!

\section{Poderíamos abordar, portanto, uma questão importante, sobre a resistência dos profissionais na adoção de um modelo científico-metodológico na avaliação?}

Prof. Dr. Armando Malheiro da Silva: Sim, porque obviamente essa resistência tem a ver com o paradigma em que ela se situa e, obviamente, que essa nossa proposta, essa nossa perspectiva de encarar a avaliação como uma operação metodológica tem um enquadramento paradigmático e, por trás, a adoção de uma mudança de paradigmas e uma adesão a um novo paradigma que é o paradigma pós-custodial, informacional e científico...- que, aliás, no Brasil vem sendo muito discutido e que se contrapõe ao paradigma que desde o século XIX, finais do XVIII, foi conformando disciplinas como a Arquivística, a Biblioteconomia, a própria Museologia, que é o paradigma custodial, e a palavra é absolutamente adequada. Aliás, há dois trabalhos do recém falecido, autor de referência, polivalente e polifacetado, chamado Umberto Eco, que, de uma forma, direi, quase caricatural e divertida, acabou por dar dois contributos para esta questão do paradigma custodial: um, no livrinho, porque é pequeno, isto é, um opúsculo, “A Biblioteca", em que reproduz uma conferência, proferida em 1980, na Biblioteca de Milão, e em que fala da experiência que teve, como leitor e usuário de bibliotecas, confessando que lhe vedavam acesso aos livros, porque as cotas eram imensas, os livros tinham de ser procurados pelos funcionários nas prateleiras, não havia acesso livre às prateleiras... E, em contraponto, expressa a surpresa que sentiu quando foi, como professor convidado, para os Estados Unidos. Aí passou a poder dormir na biblioteca, comer, acessar diretamente aos livros, tirar fotocópias e não ter que esperar dias, semanas pela informação 
pretendida; outro, no romance best-seller "O Nome da Rosa" (1980). Aqui temos uma caricatura real do que é um paradigma, o modo de ver que depois se traduz na forma como a pessoa foi ensinada ou preparada para exercer uma profissão e como ela a exerce, que é de guardar a informação como um bem precioso. Atitude comportamental determinada muito por uma visão historicista, patrimonialista e, em jeito de evolução, tecnicista. Ora, todos os bibliotecários e arquivistas - portugueses, espanhóis, etc. - mesmo aqueles que depois, nos meados da primeira metade do século XX, já sofreram com a pressão tecnológica e, sobretudo no Brasil... Um colega meu, que é um professor que estimo e atual Diretor da Escola da Ciência da Informação da UFMG, o professor Carlos Ávila, me explicou, em certa ocasião, que, no Brasil, essa questão do paradigma custodial não se fazia sentir tanto (isto segundo ele, que vem da Comunicação), devido, talvez, à forte influência norte-americana exercida por ilustres convidados como Tefko Saracevic etc, promotores do industrialismo científico-tecnocrático, plasmado em informação atual e se possível automatizada. Mas, mesmo no Brasil, há indícios da presença forte do custodialismo oitocentista, através da tradição dos Arquivos HistóricoMunicipais, dos Gabinetes de Leitura, dos Institutos Históricos-Geográficos e Heráldico-Genealógico de São Paulo, do Rio, da Bahia... O Brasil tem esta riqueza, tem uma influência norte americana e tecnológica que vai se dando nos grandes centros, sobretudo no Rio e em São Paulo, em Belo Horizonte e em Brasília, mas também custodial. E este paradigma marca a formação dos profissionais e é, por isso, que no Brasil, e de uma forma que é cada vez mais anacrônica, a graduação em Biblioteconomia, em Arquivologia e em Museologia é separada. Por quê? Porque se formos analisar, e temos - eu e minha colega Fernanda - essa questão de paradigma discutida e já publicada, inclusive em inglês, com uma contribuição no livro de homenagem ao professor Rafael Capurro (RIBEIRO; SILVA, 2016), que tem um contributo interessante para o debate dos paradigmas em Ciência da Informação. Portanto, esta questão dos paradigmas, destes dois paradigmas, o custodial e o pós-custodial, a que tenho recentemente introduzido um terceiro $-\mathrm{o}$ político e sociocultural observado especificamente no Brasil e em países da América do Sul e Central 
hispânica, que desenvolveremos, oportunamente, na reedição em breve do livro, meu e de Fernanda, "Paradigmas, serviços e mediações em Ciência da Informação" (SILVA; RIBEIRO, 2011) - é encarada muito a sério por nós e é para ajudar a compreender estas resistências, por exemplo, na avaliação. Os colegas que resistem, e eu não estou aqui a atacá-los ou a cobri-los de nomes feios, fazem-no porque, do ponto de vista mental, do modo de ver e da formação que receberam, porque o paradigma vem pela formação e depois conforma um modo de ver, não é apenas uma teoria, é um modo de ver -, estão condicionados fortemente pelo paradigma custodial e tecnicista, não conseguindo deixar de ver a informação presa a um documento e, ainda, como um bem, como algo que tem que ser ciosamente guardado. Claro que se pode acessar, mas acessar de um modo que tem que ter sempre alguns cuidados que é para não estragar o documento. E a transferência de suporte pode levantar problemas, porque aí já começa a perder autenticidade, fidedignidade e começam os questionamentos da diplomática, familiares e naturais para os historiadores medievalistas positivistas - a verdade histórica é possível com "documentos verdadeiros", autênticos... Visão a que os arquivistas custodialistas e tecnicistas são muito sensíveis e tentam inserir numa pretensa arquivística informacional. Ora, o cientista da informação não é um historiador, nem tem que ser, por isso é que tem que ter uma formação própria de nível graduado e pós-graduado, e não como eu tive, de nível especializado ou profissionalizante: eu formei-me em História e em Filosofia e depois fiz um curso de Bibliotecário-Arquivista na Faculdade de Letras da Universidade de Coimbra... Era, assim, em Portugal nos anos 1970 e 1980, e como sempre fora da década de trinta, do mesmo século, em diante. Não havia graduação na área, mas sim curso de especialização ou, mais apropriadamente, de profissionalização. Portanto, nós aqui não tínhamos graduação, tínhamos umas graduações em História, em Filosofia, em Filologia Românica, em Línguas Estrangeiras, em Direito, em Química/Ciências - áreas disciplinares potenciais de recrutamento... - e depois podíamos fazer um curso profissional, primeiro em Coimbra, onde a formação foi exclusiva durante várias décadas na Faculdade de Letras, e, no início e meados dos anos oitenta, em Lisboa e no Porto. Essa formação, hoje já inexistente no país e absolutamente 
anacrônica, seguia o modelo da École des Chartes, proposta em 1821 e constituída efetivamente em 1852, formadora do "archiviste paléographe”3 e do bibliotecário erudito, verdadeiro "templo" do paradigma custodial, historicista e patrimonialista, na Sorbonne. E os que resistem a uma avaliação científica, fazem, porque, no fundo, se conformam com uma avaliação que depois, no valor secundário, dá voz ao historiador. Eu tenho formação de historiador e, por isso, estou à vontade para formular e criticar, construtivamente, o paradigma custodial, historicista, patrimonialista e tecnicista. Não se trata, pois, de dizer que ele é mau ou bom, trata-se de afirmar que é um modo de ver profundamente datado. Nasceu e tem vigorado até hoje, mas, entretanto, estamos em uma Era nova, e a mudança do paradigma impõe-se como inevitável, apesar de ainda ser incipiente ou parecer retardada... É que a mudança não é por ruptura, como Kuhn (2013) propunha, mas pode haver mudança com coexistência de paradigmas por um tempo impreciso.

\section{O uso do paradigma, que vocês propõem, tem relação com o conceito de paradigma de Kuhn, portanto este paradigma emergente não passaria, necessariamente, por uma revolução paradigmática, para se estabelecer?}

Prof. Dr. Armando Malheiro da Silva: Sim, tem relação com Kuhn, claro. Por quê? Porque, no fundo, o novo paradigma está a ser construído de uma forma avulsa pelo mundo, com muitas resistências. As ISchools ${ }^{4}$, de algum modo, já estão no novo paradigma. Esta discussão, em torno da Ciência da Informação, significa que há uma alternativa, ou que há uma instância disciplinar que tem que se relacionar, absorver ou ter uma relação estreita com os arquivistas e com a Arquivologia, com a Biblioteconomia, com a Museologia e com os Sistemas de Informação, em suma, com as tecnologias. A Ciência da Informação não pode estar de costas voltadas para as tecnologias, ela tem que se entrelaçar à componente tecnológica, que hoje se tornou onipresente. Portanto, o novo paradigma significa uma adesão à atividade científica, ou a uma postura, eminentemente científica, e em que o foco já não é apenas o documento, porque o documento é uma consequência e não uma causa ou fenômeno causal, mas 
aquilo com que trabalhamos e que cada vez se torna mais evidente, porque muda de suporte - a informação. E não adianta querer agarrarmo-nos a um fetiche, fixarmo-nos desesperadamente ao documento, quando o que nós trabalhamos, o nosso objeto de estudo não é de verdade o documento, como não é o chip, que é assunto para o informático, mas é efetivamente a informação, ou seja, a informação que depois de produzida é materializada num suporte, se transfere de suporte uma, ou inúmeras vezes, porque isso hoje é possível e até natural, a tecnologia está a multiplicar essas transferências de suporte de uma forma espantosa, colocando-as, inclusive, na nuvem, que é um outro suporte. Portanto, se nós não aderirmos a uma nova perspectiva, em que o objeto de estudo tem que ser, muito claramente, posto como sendo a informação, não estamos preparados para encarar um futuro que já é presente. Devemos abandonar, definitivamente, o medo em usar a palavra informação. Recear ou resistir ao uso desta palavra não faz sentido. O que precisamos fazer é ousar defini-la, formular uma definição ${ }^{5}$ e, por isso, nós começamos muito cedo a dar uma definição do que é a informação. Os informáticos não se entendem, há montes de definições sobre informação e isso tem que ser clarificado. Nós, cientistas e profissionais da informação, temos que ser muito claros sobre não só o que é a informação, mas também sobre a sua relação com a Comunicação. Portanto, é muito importante que nós ponhamos a informação no centro e não na periferia do objeto de estudo da CI, estabelecendo-se, com clareza, a distinção entre informação e comunicação. É que informação humana e social produz-se e pode materializar-se, virar documento, mas isso não significa a existência imediata ou "automática" de comunicação. Informação e comunicação são as duas faces de uma mesma moeda, que não são necessariamente iguais. São diferentes, e o fato de haver informação não garante que se efetive comunicação. E a discussão deste aspecto tem implicações diretas na avaliação, que precisa estar focada e dirigida para o objeto com muita clareza, e o objeto tem que ser a informação e o fluxo da informação, ou seja, como é que ela é produzida, como é que ela é organizada, como é que ela é usada, mas, sobretudo, como é que ela é produzida, usada e armazenada, do ponto de vista de memória orgânica, na instituição produtora. Adotando-se esta perspectiva, a proposta de Schellenberg 
tinha de ser abandonada como insuficiente, ou até pueril, e substituída por algo mais robusto com critérios voltados para um máximo possível de objetividade e de cruzamentos internos: cruzar a pertinência com a densidade e, se possível, com a frequência. Na prática, o que está a suceder é que, por exemplo, a Universidade do Porto, que já está a aplicar a avaliação como operação metodológica, atinge determinados resultados e envia-os para a Torre (do Tombo) - que é o equivalente ao Arquivo Nacional e ao CONARQ - dando apenas conhecimento sem necessidade de validação, pois possui autonomia para aplicar os resultados livremente. Esses resultados podem traduzir-se numa portaria ou numa tabela de temporalidade, que são, clara e indiscutivelmente, a consequência de uma abordagem científica e não "consensualista" ou impressionista... É certo que a Torre tem tido muita dificuldade em aceitar este tipo de abordagem e, por causa disso, tem seguido caminhos ínvios, em que mistura um pouco da perspectiva do Porto com a macro-avaliação do falecido Terry Cook e, ainda, resquícios fortes dos valores primário e secundário... Eu aguardo o dia em que os colegas do Arquivo Nacional se disponham a discutir seriamente a avaliação, como operação metodológica, e a macro-avaliação, comparando e apreciando pontos fortes e fracos... Num debate, que se fez há uns anos na Casa do Infante, no início deste século, até os críticos mais obstinados tiveram de reconhecer que a introdução de critérios e a sistematização conseguida através de grelha combinatória eram um ganho seguro no sentido de objetivar o processo avaliativo. Mas, os críticos têm, por exemplo, dificuldade em aceitar as taxas de eliminação que a avaliação que propomos atinge: são possivelmente mais baixas do que as "forjadas" para a portaria, ou para a tabela de temporalidade, destinadas a "aliviarem os Serviços". É indesmentível o que se tem visto, no Brasil e aqui, com as famosas portarias. Muitas foram "feitas literalmente a olho", ou seja, desta maneira: "ah, isto não é preciso, ah, são muitos, a série é muito grande - é até melhor eliminar, porque não se tem espaço". Sobretudo, agora, também tem que se pensar que temos que avaliar para o digital, o que implica discutir em terabytes, e já não em metros lineares, o que faz uma estranha e enorme diferença... Portanto, com o novo paradigma e com esta nossa proposta de avaliação, eu não tenho que discutir espaço, eu tenho 
é que saber se a informação que conservo é pertinente para a memória da instituição, ou da entidade produtora, ou não.

\section{Ótimo entrarmos no assunto dos ambientes digitais, porque há toda uma nova área surgindo, de Ciência dos Dados, do objeto enquanto 'Dado' versus o objeto 'Informação'.}

Prof. Dr. Armando Malheiro da Silva: Nós julgamos que temos isso mais ou menos resolvido e vemos, até com agrado, que o Luciano Floridi (2010), de algum modo, colabora conosco, por outra via, através do seu ângulo particular: o plano filosófico, da filosofia analítica, da discussão do que é o conhecimento e da questão do sentido. Esta discussão sobre os dados não é tão simples e linear como os informáticos supõem, porque eles olham para isto de uma forma muito pueril e instrumental, querem separar uma informação, que está numa tabela, de uma informação que está num texto e, depois, do conhecimento, que é aquela informação que eu cognitivamente trabalho e à qual acrescento valor quase no plano da genialidade. Os informáticos são pessoas que tem que traduzir as coisas em termos concretos e agarram-se ao ramo e esquecem a árvore, e, muitas vezes, a floresta. E esquecem, sobretudo, a filosofia, o poder das palavras, dos conceitos. Informação vem de informare, que queria dizer no latim "dar forma", dar forma a ideias, dar forma a fatos, dar forma a qualquer coisa. Por sua vez, o conhecimento tem a ver com a racionalidade, com conhecer, compreender. A compreensão é, também, complementar da forma, porque eu quero dar forma a uma ideia, a uma intuição ou a uma apreciação que tive, isto é, dar forma a um ato compreensivo. Portanto, informação e conhecimento têm muito pouco por onde fugir um do outro, e a questão do dado também é igual. Estamos a falar de quê? De uma data com sentido? Se é uma data com sentido, que está numa tabela, ela é informação. Portanto, o dado é dado porque é um número, e eu estou a lhe chamar dado, porque é um número. Este tipo de distinção que os informáticos fazem, a mim diz pouco. Se ajuda ao informático para entender-se consigo e com os colegas, bom para o informático, mas, como profissional e, pretensamente, como cientista da informação, dado, entendido, e isto é muito 
importante, como uma representação mental e emocional codificada, é informação. E, inclusive, eu dou aulas de Introdução aos Sistemas de Ciência da Informação (disciplina da Licenciatura em Ciência da Informação das Faculdades de Letras e de Engenharia da Universidade do Porto), com um colega da Engenharia, que tem esta posição de partida e decorrente da sua formação, mas que conseguiu, numa conversa preparatória, porque damos a disciplina juntos, entender perfeitamente isto. O meu colega, Professor Antônio Lucas Soares, conseguiu entender que, a partir do momento que estou a falar de sentido, estou a falar de informação e distinguir dado de uma frase, ou de um texto literário, ou de um poema, é inútil e até absurdo. Claro que são registros diferentes, mas é informação. Um texto literário é um texto literário, um relatório de um técnico de águas, que reporta, ao Município, uma inundação, não é um texto literário, mas é informação, na medida em que é um conjunto de representações mentais codificadas através das palavras, números, localizações geográficas, etc.

\section{A informação seria, por fim, o objeto da avaliação?}

Prof. Dr. Armando Malheiro da Silva: É evidente...é evidente. Sem subterfúgios ou complicações, podemos admiti-lo de imediato.

\section{E como poderíamos diferenciá-lo do dado, enquanto objeto de estudo?}

Prof. Dr. Armando Malheiro da Silva: Vamos ao ponto que aflorou da Ciência dos Dados: se esses dados são os bytes, os terabytes etc, estamos a falar de informática e, então, a Ciência dos Dados é uma nova conformação dentro do "cluster disciplinar" dos Sistemas da Informação e da Informática e das Ciências da Computação, e, portanto, é uma área tecnológica. Agora, se estamos a falar de uma Ciência dos Dados, em que o dado também já comporta sentido, não vejo que haja necessidade de uma Ciência dos Dados, porque já temos a Ciência da Informação. Convém repetir isto: não há necessidade de uma nova ciência social denominada Ciência dos Dados, porque a Ciência da Informação cumpre 
esse desiderato. Agora, se os que falam da Ciência dos Dados, estão a pensar nos servidores, nos datacenter e querem uma Ciência que é um complemento tecnológico, que é uma Ciência Tecnológica, que trabalha com energias, com chips, com circuitos, com sensores e com software adequado a bases de dados gigantescas, há que distinguir planos e ajudá-los a que eles percebam melhor do que estão falando... Vejamos melhor, tomando o exemplo dos sensores: eles captam vibrações físicas, luz, movimento, etc., que são de imediato convertidos em uma representação codificada e entendida em código humano. Já no Dicionário Eletrônico de Terminologia de Ciência da Informação (DeltCI) ${ }^{6}$, faço a distinção há muito tempo: há dado de sentido 1 e dado de sentido 2. Para nós, dado no sentido 1, que é o sentido de uma representação mental, é informação; agora, dado no sentido 2, por exemplo, um sensor que capta um impulso físico, elétrico, cósmico, vulcânico, sísmico, esse impulso não é informação, porque ele é físico, mas, ao ser convertido num código humano e social começa a ser informação. No sentido 1, dado é seguramente informação: quando, por exemplo, um sismógrafo começa a fazer aquelas alterações muito acentuadas de riscos, isso já é informação, porque é um código que tem leitura, porque está a representar algo, ou seja, é um dado ou informação. No sentido 2, o dado é físico, sendo, então, matéria de estudo no domínio da Física, da Vulcanologia, da Informática, da Tecnologia. Portanto, separar dado de informação é um exercício inútil. Repito isto de uma forma provocatória, porque começo também a ter pouca paciência para ter que explicar isto inúmeras vezes, pois isso é tão óbvio para mim, e ninguém consegue contrapor ou contra-argumentar solidamente. Como é que o dado não é uma representação? É desconhecer a Semiótica, é desconhecer um pouco também a linguagem e a Linguística. Se é algo que sai do meu cérebro, como é que não é uma representação? Então, como é que é algo que não tem a ver com o sentido? Quando eu penso numa data, 1957, isto é um número? Claro que não, porque isto tem a ver com a minha vida, pode ser o ano de meu nascimento. Dirão: "Ah é um número, é um dado". Insisto eu: "É uma informação, desculpe”. Mas, dirão a seguir: “Ah, mas eu não sei o que 1957 quer significar...". Respondo: “É natural porque é apenas receptor, mas para definir informação eu não posso depender apenas do 
entendimento feito por quem lê, escuta e vê. Tenho de ter em consideração, em primeira linha, o produtor de sentido, o emissor, e quem escreve um número desses, atribuiu-lhe sentido. Atribui sempre sentido, logo temos informação. Floridi diz isto, de uma outra maneira".

\section{Floridi fala sobre a informação semântica...}

Prof. Dr. Armando Malheiro da Silva: Ele fala da informação semântica, e eu falo de sentido, que só há informação se houver sentido. Floridi usa um termo que parece ser melhor entendido pelos informáticos...

\section{Para finalizar, voltando um pouco para o foco da nossa conversa, a Avaliação do Fluxo Informacional, e pensando nos estudos de caso, tanto em Portugal como em outros países.}

Prof. Dr. Armando Malheiro da Silva: As aplicações da avaliação, como uma operação metodológica, não se podem dizer que existam em grande quantidade. E há aqui, de fato, um conflito e um campo de batalha, digamos, entre aspas, uma batalha entre duas perspectivas bem diferentes. Se encaramos a avaliação como uma operação metodológica, ela exige tempo, ela exige atenção, concentração e espírito científico, e não se pode praticá-la, com a ideia simplista, de produzir uma tabela de temporalidade, uma portaria, que elenca um conjunto de séries que depois são para eliminar e aliviar as instituições e as pessoas que lá trabalham. Não se pode ir com esse espírito. Tem sido aplicado, na Universidade do Porto, e é um processo que está em marcha, tem se aplicado em algumas entidades que vêm pedindo colaboração, ou onde antigos alunos nossos de Licenciatura são funcionários e decidiram aplicar a abordagem científica, ou, ainda, através de doutorandos que colocam a avaliação no foco de suas teses. Penso que, no Brasil, começa a ser discutida de uma forma séria, embora vá encontrar resistência, porque o CONARQ e o Arquivo Nacional, provavelmente, olham para esta perspectiva e para a ideia de uma avaliação de fluxo como algo bizarro. Os arquivistas, se calhar, com a formação e com o 
paradigma que têm, sentem-se muito pouco à vontade, porque é mais cômodo elaborar uma tabela de temporalidade, porque permite um grau de subjetividade que é disfarçado como sendo um trabalho muito cansativo e muito difícil do arquivista, mas que, no fundo, sabemos que é um trabalho muito pouco consistente, porque a respectiva cientificidade resume-se a dizer se vai interessar ao historiador. Só que o problema não está no historiador, está em averiguar se deve ficar na memória da Organização. E como é que eu sei isso? Cruzando critérios. A aplicação destes critérios é o ponto nevrálgico e este enfoque tem que ser levado a sério. Portanto, as pessoas resistem, eu tenho encontrado resistência sim, porque as pessoas assustam-se. Aqui em Portugal, o Organismo governamental que tutela a política arquivística nacional está, neste momento, a implementar uma macroestrutura-funcional, onde não está o orgânico, mas está o funcional, o que já é para nós inaceitável, porque nós não concebemos o fluxo informacional sem um contexto orgânico-funcional. Portanto, tudo que se desliga do orgânico-funcional, para nós, é inaceitável, e ninguém me consegue provar o contrário. Esse projeto em curso, foi inspirado na Macro-avaliação de Terry Cook, na avaliação canadiana, que entusiasmou alguns colegas nossos de Lisboa, que foram muito seduzidos pelo canto do cisne canadiano. "Canto" esse que, na verdade, até é muito contextual e que, depois, tem uma dose de abordagem social e política, que também seduz. A deriva ideológica e pósmodernista é temerária, e nós, no Porto, rejeitamo-la, mas, compreendo que os canadianos estivessem e estejam ainda dispostos a se dar ao luxo dessas derivas, porque, na verdade, eles também são muito organizados e, quando se tem uma administração muito organizada, numa população pequena - o Canadá tem muito território e pouca gente - a avaliação é muito mais fácil de fazer, porque não há massas documentais acumuladas, ao contrário do que se passa nos Estados desorganizados e opacos, como o Estado brasileiro, o Estado português e outros Estados onde se acumularam, de forma anárquica, até por vantagem e conveniência das administrações e de seus funcionários, que apostavam e apostam na falta de transparência para protegerem a sua ineficácia, incompetência ou corrupção sistêmicas. Há países dotados de uma organização estatal e administrativa sofisticadas, que contam também com o papel ativo da 
opinião pública, que a comunicação social estimula a uma forte participação em prol das práticas políticas de transparência. Por isso, no Canadá, os arquivistas para valorizarem e atualizarem o seu perfil profissional, alinharam pelo pósmodernismo e relativismo, mas, trabalham com uma sólida noção orgânicofuncional e conferem importância à memória organizacional ligada à transparência. E a macro-avaliação incorpora estes elementos positivos. Nós, aqui em Portugal, e outros em diferentes latitudes, temos de evoluir para essa mentalidade "civilizada" através, concretamente, do reforço da cientificidade, insistindo muito, muito e muito na questão da organicidade. E, por isso, é que nós somos muito críticos e não aceitamos o funcional sem o orgânico, e sabemos que, obviamente, ao metermos a avaliação do fluxo como uma operação metodológica, causamos atração e repulsa: uns vão buscar e "acham graça" ao critério da densidade, ao mesmo tempo, que rejeitam o resto, ora, tal atitude é condenável. Não se pode achar graça a um critério e não achar graça a outro. Não se brinca assim, não é? Outros sabem que o modelo schellenberguiano está morto, mas não sentem coragem para dar um pulo em frente e refugiam-se em derivações laterais como a canadiana; e há os que continuam a virar o rosto para o lado...Os critérios, todos eles, são "teclas" de um teclado, para produzir uma música harmoniosa. Portanto, eles estão todos articulados e tem que ser aplicados com muito rigor. Claro que, no final, dá um número possivelmente mais elevado de documentação a conservar. Paciência. Aí está o digital a relativizar, e muito, os futuros problemas de espaço físico. Tem que se criar e envolver as empresas de tecnologia, sensibilizá-las para a conservação permanente, para que enfrentem e resolvam os problemas de obsolescência dos materiais, transferências seguras de suporte, no caso do digital, etc.

\section{E, aqui na Universidade do Porto, já se aplica a avaliação do fluxo informacional, correto? Como tem sido esta aplicação?}

Prof. Dr. Armando Malheiro da Silva: Sim. Desde que ela começou a ser proposta, sim. Agora, com algumas resistências de Lisboa, mas, isso não nos 
afeta, porque nós aplicamos a avaliação numa perspectiva científica. E, portanto, não temos nenhuma evidência que a contrarie. Até o momento, ninguém nos veio dizer que esta forma e esta perspectiva de encarar a avaliação como uma avaliação metodológica está errada. E, como não nos vêm mostrar, de forma científica, que ela está errada, aconselhamos os colegas resistentes a ter a humildade de analisarem conosco o assunto, porque, da nossa parte, há total abertura para isso. Queremos dialogar, mas queremos um diálogo fundamentado, um diálogo consistente, sério. E nós já vimos isto: cada vez que eu falo da avaliação, e, cada vez que se apresentam processos de aplicação da avaliação como operação metodológica, fica evidente que ela tem uma consistência, que o modelo schellenberguiano não possui, e, comparado com a macro-avaliação, esta tem a fragilidade da deriva relativista e pós-moderna que a subjetiviza. Mas, no essencial, há convergência: a Macro-avaliação valoriza o contexto, e nós partimos do mesmo pressuposto. Ambas as propostas assentam no contexto orgânico-funcional em que a informação tem que ser guardada pela importância que tem para a instituição ou para o produtor. A diferença surge quando a Macro-avaliação evoca a Sociedade e a inclui no processo de avaliação. Tudo bem, não tenho nada contra a Sociedade, mas não se pode exaltar a Sociedade apagando a importância do orgânico, e é isso que desencadeia a deriva ideológica com a qual eu estou em ruptura completa, porque isto não é científico. Científico, no sentido equilibrado do conceito, e não no anacronismo positivista, que rejeito plenamente.

\section{Isto, portanto, prejudicaria uma abordagem científica...}

Prof. Dr. Armando Malheiro da Silva: Claro. Agora, a abordagem científica, obviamente, também não é neutra. Não somos ingênuos e, se estamos a falar de Ciência Social, a neutralidade do sujeito investigador é uma miragem, mas também não somos ingênuos ao ponto de pensar que quando se invoca a Sociedade, o que se está a fazer, senão opções ideológicas indisfarçáveis? Há um arquivista sul-africano, Verne Harris, que, num artigo na Archival Science, glosou esta "tese": "Não, nós, depois do Apartheid, temos que valorizar a 
informação que é dos negros, porque durante muito tempo só se guardava a dos brancos" (HARRIS, 2002). Então, quer dizer, uma avaliação em função do poder. O poder branco e, agora, o blackpower, porque agora este é melhor e mais legítimo que aquele... Certo, eu também sou anti-racista, acho condenável o Apartheid, mas, não é por causa do meu anti-racismo que eu devo conservar ou eliminar informação. Eu tenho que ir à África do Sul e perguntar: a documentação da instituição tal, é de pertinência A, para a memória da instituição, ou não? Sendo para a instituição, é para a sociedade, o que de alguma maneira já introduz o primado social que Cook e os pós-modernistas tanto apreciaram e apreciam. A defesa que fazemos, no Porto, de um posicionamento científico no estudo amplo, incluindo a avaliação da informação, afasta-nos do relativismo e de Terry Cook, mas, também é preciso sublinhar, para concluir, que não entendemos a Ciência como uma panacéia. No entanto, ela é o caminho possível da busca da verdade, sempre passível de ser refeita e insistentemente buscada... A ciência firma-se no diálogo, no refazer, na atitude de Galileu e, no velho espírito da ciência moderna, que continua válido e atual, ou no exemplo de Charles Darwin, que tardou a publicar a sua monumental pesquisa sobre a evolução e "A Origem das Espécies", receoso da polêmica que iria causar, sobretudo nos círculos religiosos cristãos. Porém, as evidências, que revelou e formulou, constituem um discurso científico modelar.

\section{Referências}

ECO, Umberto. O nome da rosa. Lisboa: DIFEL, 1980.

FLORIDI, Luciano. Information: a very short introduction. New York: Oxford University Press, 2010.

HARRIS, Verne. The archival sliver: power, memory, and archives in South Africa. Archival Science, v. 2, n. 1-2, p. 63-86, 2002. Disponível em:

<http://www.nyu.edu/pages/classes/bkg/methods/harris.pdf>. Acesso em: 29 set. 2016.

KUHN, Thomas S. A estrutura das revoluções científicas. 12. ed. São Paulo: Perspectiva, 2013. 
RIBEIRO, Fernanda; SILVA, Armando Malheiro da. A avaliação de informação: uma operação metodológica. Páginas A\&B: arquivos e bibliotecas, Lisboa, n. 14, p. 7-37, 2004.

RIBEIRO, Fernanda; SILVA, Armando Malheiro da.The epistemological maturity of information science and the debate around the paradigms. In: KELLY, Matthew; BIELBY, Jared (Ed.). Information cultures in the digital age: a festschrift in honor of Rafael Capurro. [S. 1.]: Springer VS, 2016.

SILVA, Armando Malheiro da. A informação. Da compreensão do fenómeno e construção do objecto científico. Porto: Edições Afrontamento, 2006.

SILVA, Armando Malheiro da; AZEVEDO PINTO, Maria Manuela Gomes de. Um modelo sistémico e integral de gestão da informação nas organizações. In: CONGRESSO INTERNACIONAL DE GESTÃO DA TECNOLOGIA E SISTEMAS DE INFORMAÇÃO, 2., São Paulo, 2005. Actas... [S.1.: s.n.], 2005.

SILVA, Armando Malheiro da; RIBEIRO, Fernanda. Information evaluation: a scientific and comprehensive approach. In: JAMIL, George Leal; MALHEIRO, Armando; RIBEIRO, Fernanda (Ed.). Rethinking the conceptual base for new pratical applications in information value and quality. Hershey: IGI Global, 2014. p. 19-41.

SILVA, Armando Malheiro da; RIBEIRO, Fernanda. Paradigmas, serviços e mediações em ciência da informação. Recife: Néctar, 2011.

Recebido: 13/12/2016

Aceito: 18/01/2017

\footnotetext{
${ }^{1}$ A obra também possui edição em português - BRUYNE, P. de; HERMAN, Jacques; SCHOUTHEETE, M. de. Dinâmica da pesquisa em ciências sociais: os pólos da prática metodológica. 5. ed. Rio de Janeiro: F. Alves, 1991.

${ }^{2}$ Organicidade é a "capacidade de toda e qualquer Organização (baseada ou mediada por estrutura administrativa e funcional ou orgânico-funcional) agir em todos e diversos níveis para atingir, concretizar e rentabilizar objectivos centrais/genéricos e específicos ou ligados à natureza do 'segmento' públicopolítico, político-social e sócio-económico da Organização”. (SILVA, Armando Malheiro; AZEVEDO PINTO, Maria Manuela Gomes de. Um modelo sistémico e integral de gestão da informação nas organizações. In: CONTECSI- Congresso Internacional de Gestão da Tecnologia e Sistemas de Informação, 20, São Paulo, 2005 Actas do congresso. 2005). Ver também o verbete "Organicidade" no Dicionário Eletronico de Terminologia em Ciência da Informação. Disponível em < https://paginas.fe.up.pt/ lci/index.php/1746>. Acesso em 25 set. 2016.

3 Formação de Arquivista-Paleógrafo, disponível em <http://www.enc-sorbonne.fr/fr/cursus/diplomearchiviste-paleographe> Acesso em 18 set. 2016.

4 A organização Ischools é um consórcio de Escolas de Ciência da Informação, dedicada ao desenvolvimento da área da Informação. A Universidade do Porto é membro do consórcio desde 2013. Disponível em <http://ischools.org/> Acesso em 10 set. 2016.
} 
Entrevista: Armando Malheiro da Silva

Moisés Rockembach

${ }^{5}$ Entendida como o "conjunto estruturado de representações de representações mentais codificadas (signos, símbolos), socialmente contextualizadas e passíveis de serem registadas num qualquer suporte material (papel, filme, banda magnética, disco compacto, etc.), comunicadas de forma assíncrona e multidireccionada" (SILVA, 2006).

${ }^{6}$ Ver Dado (1), disponível em <https://paginas.fe.up.pt/ lci/index.php/1704> Acesso em 10 set. 2016 e Dado (2), disponível em <https://paginas.fe.up.pt/ lci/index.php/1705> Acesso em 10 set. 2016. 